\title{
Adequacy of discharge summaries prepared by junior medical residents in a university hospital
}

\author{
Ibrahiem Saeed Abdul-Rahman \\ Department of Internal Medicine, King Fahd Hospital of the University, University of Dammam , Al-Khobar - Saudi Arabia
}

Email address:

isaeed@ud.edu.sa (I. S. Abdul-Rahman)

\section{To cite this article:}

Ibrahiem Saeed Abdul-Rahman. Adequacy of Discharge Summaries Prepared by Junior Medical Residents in a University Hospital. Clinical Medicine Research. Vol. 1, No. 1, 2012, pp. 1-6. doi: 10.11648/j.cmr.20120101.11

\begin{abstract}
Discharge summaries are intended to transfer important clinical information from inpatient to outpatient settings and between hospital admissions. Complete, accurate, and timely discharge summaries can communicate important information back to the outpatient (OPD) physician, prevent adverse events and reduce readmission to hospital. However, discharge summaries are not always given the priority it deserves. Too often, discharge summaries contain insufficient or unnecessary information and fail to reach the OPD physician in time for the patient's follow-up visit. We evaluated discharge summaries produced by first-year medical residents (R1) for their completeness and accuracy. Consecutive discharge summaries prepared by R1 residents for patients discharged from internal medicine wards were retrospectively evaluated by two independent reviewers for presence and accuracy of essential items described by the Joint Commission for Hospital Accreditation. One-hundred and thirty-two discharge summaries were assessed for completeness and accuracy. Most items were incompletely reported with a given item missing in $2.3 \%-91.7 \%$ of all discharge summaries. Inaccuracies of discharge summaries when compared to the patient chart as a reference standard ranged from $8.5 \%$ for final diagnosis to $50.9 \%$ for anticipated problems and suggested interventions with a mean of $29.6+13.3 \%$.Only $18.2 \%$ of the discharge summaries were written within 48 hours of patient discharge $(\mathrm{p}<0.001)$. The availability of a finalized (typed and signed) discharge summary at the first post-discharge visit was low (12.1\%) and remained poor at 4 weeks (50.8\%). Conclusion: Discharge summaries prepared by R1 physicians are grossly inadequate at documenting most of the essential domains described by the Joint Commission for Hospital Accreditation. Our findings will aid in the development of educational interventions for residents.
\end{abstract}

Keywords: Discharge Summaries, Medical Residents, Opd, The Joint Commission For Hospital Accreditation

\section{Introduction}

Discharge summary is a vital tool for transferring information between the internist and outpatient department (OPD) physician, but it isn't always given the priority it deserves. Too often, research suggests, summaries contain insufficient or unnecessary information and fail to reach the OPD physician in time for the patient's follow-up visit, if they arrive at all. The discharge summary is the most common method for documenting a patient's diagnostic findings, hospital management, and arrangements for postdischarge follow-up. The Joint Commission on Accreditation of Healthcare Organizations (JCAHO) (1) requires that discharge summaries be completed within 48 hours of hospital discharge and that they include the following elements: "the reason for hospitalization; significant findings; procedures performed and care, treatment, and services provided; the patient's condition at discharge; and information provided to the patient and family, as appropriate (2). Moreover, a standard approach to handoff communications is included among JCAHO's national patient safety goals, as is the reconciliation of medications at care transitions (3).

Despite the availability of these performance standards, the extent to which physicians successfully transfer timely and accurate patient information at hospital discharge is uncertain. Discharge summaries also frequently suffer in quality by being too long and containing unnecessary information or too short and lacking the necessary data $(4,5)$. Experts advised keeping summaries short for easy readability - ideally no more than two pages long - and including information that is most relevant for the OPD physician (6). However, it seems that even with technological advances that improve discharge processes, we're still a long way off from having a perfect discharge summary. We performed a 
systematic review of the patients' charts to characterize the types and prevalence of deficits in discharge summaries written by first-year medical residents (R1) and information transfer between hospital-based and OPD physicians at hospital discharge. The study that extended from August 2009 throughout July 2012 also evaluated the quality of discharge summaries using the patient's charts as a reference standard.

\section{Methods}

\subsection{Assessment of the Completeness and Accuracy of Discharge Summaries}

The charts of patients consecutively discharged from Internal Medicine Units (3 Units) at King Fahd University Hospital between August 2009 and July 2012, were reviewed for eligibility. The target sample was 50 charts from each, for a total of 150 charts. Charts were eligible for inclusion if the discharge summary for that admission was written by R1-Internal Medicine residents within the first 6 months of their Internal Medicine Program. Charts were excluded if the patient was discharged to a destination different than the one of admission (e.g. discharged to a new placement at a long term care facility, transferred from the medical unit to a different hospital ward, or transferred to a rehabilitation or palliative care unit). Data were abstracted independently in duplicate by two investigators regarding the presence of the following essential domains described by the Joint Commission on Accreditation of Healthcare Organizations and Society of Hospital Medicine (1):

- Problem that led to hospitalization

- Key findings

- Test results

- Final diagnoses (primary and secondary)

- Brief hospital course

- Reason for medication change(s)

- Condition at discharge

- Discharge destination

- Medications at discharge

- Follow-up appointments and proposed management plan

- Anticipated problems and suggested interventions

- Pending laboratory work and tests

- Recommendations of subspecialty consultants

- Documentation of patient education

The investigators recorded whether these items were present, and when present, assessed the accuracy of these items compared to the patient chart as a reference standard. Discrepancies between the investigators were resolved by consensus.

\subsection{Statistical Analysis}

The presence and accuracy of each component of the discharge summary are reported as proportion and 95 percent confidence intervals (CIs). For some hospitalizations, certain items of the discharge summary were not relevant (e.g. "reason for medication changes" if no changes had been made), and in such cases were excluded from the denominator, i.e. were not counted as missing. The target sample size for this component of the study was calculated based on a desired $95 \% \mathrm{CI}$ for the proportion of charts for which a given item was present/absent of $+/-0.1$, using an expected proportion of 0.5 since $95 \%$ CIs are widest for proportions of 0.5 (i.e. a conservative estimate). Chancecorrected inter-rater agreement regarding the accuracy of each component of the discharge summary was assessed using the kappa statistic (7).

\section{Results}

We reviewed 150 discharge summaries written by 17 Internal Medicine residents during their first-year training program (August 2009 -July 2012). Eighteen discharge summaries were excluded from the study since a given item was not applicable for the patient's stay in hospital (e.g. "Reason for medication change(s)" would not be relevant for a patient whose medications were not changed during that hospitalization). In the remaining 132 discharge summaries were eligible to enter the study.

Most items were incompletely reported with a given item missing in $2.3 \%-91.7 \%$ of all discharge summaries (Table 1). Items that are most frequently missing are: reasons for medication changes, anticipated problems and suggested interventions, pending laboratory work and documentation of patient education, in $57.6 \%, 59.8 \%, 84.8 \%$ and $91.7 \%$ respectively. Final diagnosis and medications at discharge were present in almost all discharge summaries $(97.7 \%$ and $96.2 \%$ respectively). Inaccuracies of discharge summaries when compared to the patient chart as a reference standard ranged from $8.5 \%$ for final diagnosis to $50.9 \%$ for anticipated problems and suggested interventions with a mean of $29.6+13.3 \%$ (Table 2 and Figure 1). Some discharge summaries were excluded in the denominator because information for a given item (e.g. discharge medication list) was simply missing, since accuracy could only be assessed if information was present (Figure 1). Only $18.2 \%$ of the discharge summaries were written within 48 hours of patient discharge $(p<0.001)$. In the remaining $81.8 \%$ of discharge summaries, residents had to complete their notes several weeks after patients' discharge (as a prerequisite for approving their vacation) (Figure 2). The availability of a finalized (typed and signed) discharge summary at the first post-discharge visit was low $(12.1 \%)$ and remained poor at 4 weeks $(50.8 \%)$, affecting the quality of care in approximately $75 \%$ of follow-up visits and contributing to OPDphysician dissatisfaction.

Problem: problem that led to hospitalization, Diagnosis: final diagnosis, Rx changes: reason for medication changes, Discharge: condition at discharge, Plan: follow-up appointments and proposed management plan, Suggestions: anticipated problems and suggested interventions, Pending: pending lab results, Education: documentation of patient's education. 


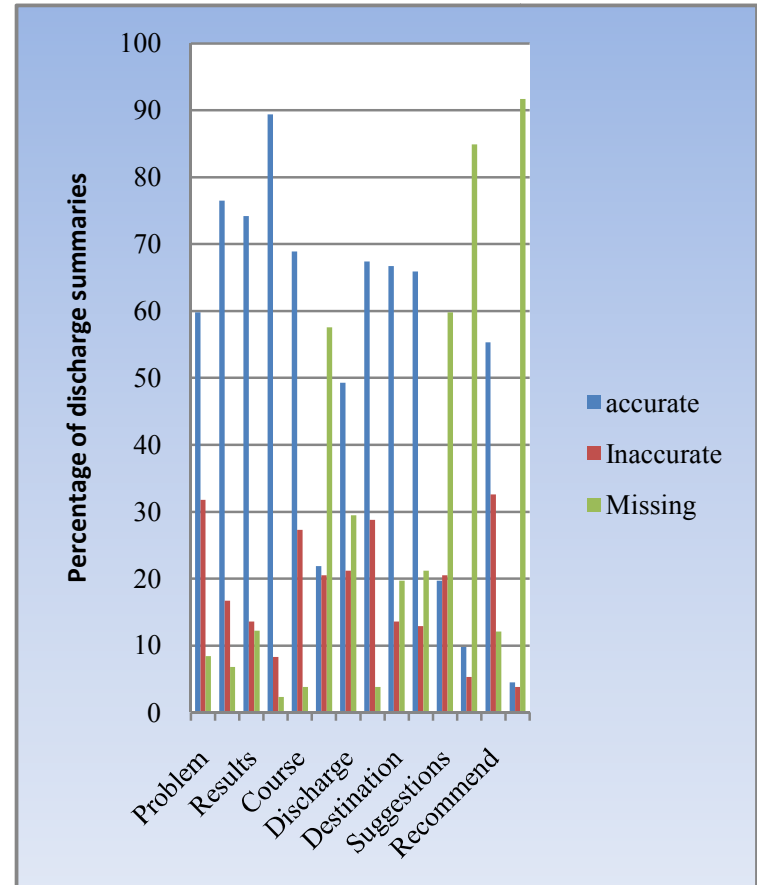

Figure 1. Inaccurate informations in discharge summaries when compared with the patients' charts as a reference standard.

Table 1. Frequency of missing information in discharge summaries.

\begin{tabular}{|c|c|c|}
\hline & Missing (n) & $\%(95 \% \mathrm{CI})$ \\
\hline $\begin{array}{l}\text { Problem that led to } \\
\text { hospitalization }\end{array}$ & 11 & $8.3(2.5-10.2)$ \\
\hline Key findings & 9 & $6.8(1.7-8.4)$ \\
\hline Test results & 16 & $12.1(7.7-13.6)$ \\
\hline Final diagnosis & 3 & $2.3(0.8-4.6)$ \\
\hline Brief hospital course & 5 & $3.8(0.9-6.4)$ \\
\hline $\begin{array}{l}\text { Reason for } \\
\text { medication change(s) }\end{array}$ & 76 & $57.6(21.7-41.1)$ \\
\hline Condition at discharge & 39 & $29.5(18.4-33.6)$ \\
\hline Discharge destination & 26 & $19.7(13.5-21.7)$ \\
\hline Medications at discharge & 5 & $3.8(0.9-7.4)$ \\
\hline $\begin{array}{l}\text { Follow-up appointments } \\
\text { and proposed } \\
\text { management plan }\end{array}$ & 28 & $21.2(14.6-23.1)$ \\
\hline $\begin{array}{l}\text { Anticipated problems } \\
\text { and suggested interventions }\end{array}$ & 79 & $59.8(22.6-43.5)$ \\
\hline $\begin{array}{l}\text { Pending laboratory work and } \\
\text { tests }\end{array}$ & $d_{112}$ & $84.8(29.3-44.2)$ \\
\hline $\begin{array}{l}\text { Recommendations of } \\
\text { subspecialty consultants }\end{array}$ & 16 & $12.1(7.7-13.6)$ \\
\hline $\begin{array}{l}\text { Documentation of } \\
\text { patient education }\end{array}$ & 121 & $91.7(39.7-66.8)$ \\
\hline
\end{tabular}

Table 2. Frequency of inaccurate information in discharge summaries, when information was present.

\begin{tabular}{|c|c|c|c|}
\hline \multirow{2}{*}{\multicolumn{2}{|c|}{$\begin{array}{l}\text { Problem that led to } \\
\text { hospitalization }\end{array}{ }_{42 / 121}$}} & $\%(95 \% \mathrm{CI})$ & \multirow{2}{*}{$\begin{array}{l}\begin{array}{l}\text { Inter-rater } \\
\text { reliability } \\
\text { (kappa) }\end{array} \\
0.73\end{array}$} \\
\hline & & $34.7(23.6-42.9)$ & \\
\hline Key findings & $22 / 123$ & $17.9(10.3-20.6)$ & 0.63 \\
\hline Test results & $18 / 116$ & $15.5(8.7-16.2)$ & 0.58 \\
\hline Final diagnosis & $11 / 129$ & $8.5(3.8-15.3)$ & 0.46 \\
\hline hospital course & $36 / 127$ & $28.3(19.5-36.7$ & 0.66 \\
\hline \multicolumn{2}{|c|}{$\begin{array}{l}\text { Reason for medication } \\
\text { change(s) }\end{array}$} & \multicolumn{2}{|c|}{$48.2(30.1-55.7) 0.84$} \\
\hline \multicolumn{2}{|c|}{ Condition at discharge $28 / 93$} & \multicolumn{2}{|c|}{$30.1(20.5-38.1) 0.71$} \\
\hline \multicolumn{2}{|c|}{$\begin{array}{l}\text { Medications at } \\
\text { discharge }\end{array}$} & \multicolumn{2}{|c|}{$29.9(20.3-38.5) 0.69$} \\
\hline \multicolumn{2}{|c|}{ Discharge destination $18 / 106$} & $17.0(10.3-18.8)$ & 0.63 \\
\hline $\begin{array}{l}\text { Follow-up } \\
\text { appointments an } \\
\text { proposed } \\
\text { management plan }\end{array}$ & ind $_{17 / 104}$ & $16.3(9.1-16.5)$ & 0.60 \\
\hline \multicolumn{2}{|c|}{$\begin{array}{l}\text { Anticipated problems } \\
\text { and suggested interven-27/53 } \\
\text { tions }\end{array}$} & $50.9(29.4-56.4)$ & 0.89 \\
\hline \multicolumn{2}{|c|}{$\begin{array}{l}\text { Pending laboratory } \\
\text { work and tests }\end{array}$} & $35(23.8-44.2)$ & 0.73 \\
\hline $\begin{array}{l}\text { Recommendations } \\
\text { subspecialty } \\
\text { consultants }\end{array}$ & of $43 / 116$ & $37.1(25.3-46.4)$ & 0.78 \\
\hline $\begin{array}{l}\text { Documentation } \\
\text { patient education }\end{array}$ & of $_{5 / 11}$ & $45.5(27.8-52.3$ & 0.81 \\
\hline
\end{tabular}

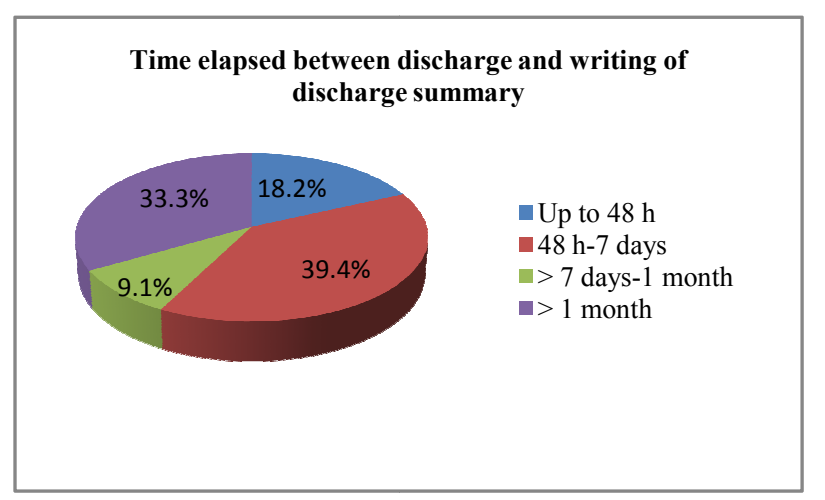

Figure 2. Time elapsed between patients' discharge and writing of discharge summary.

\section{Discussion}

Despite the critical role that discharge summaries play in care transitions (3-6) and the existence of Joint Commission standards mandating certain discharge summary components (1-3) ours is the first study in the area to specifically define and document the defects in items and quality of discharge summaries written by R1 medical residents. Overall, preliminary results demonstrate that the discharge summaries within our sample do not adhere well to most of the Joint Commission standards. However, given the discharge summary's pivotal communication role in care transitions, even a small frequency of omitted patient discharge condition information is a concern and may influence patient safety. In this study, we offer reliable, specific, con- 
sensus-based definitions of each Joint Commission component. Remarkably, we are the first study in our area to do so. These definitions can be utilized to reliably and specifically abstract discharge summaries to document compliance with Joint Commission standards. Reliable and specific definitions such as these will be helpful in ensuring adequate, reproducible assessments of discharge summary completeness in the future. A structured, standard discharge summary form ensures that all the important information is included and allows the receiving physician to more quickly identify how to respond to the patient's hospitalization. The Joint Commission on Accreditation of Healthcare Organizations and Society of Hospital Medicine (1, 3, 8) mandates that discharge summaries contain certain components: reason for hospitalization, significant findings, procedures and treatment provided, patient's discharge condition, patient and family instructions, and attending physician's signature. Also, a few health care groups, including the National Quality Forum (NQF) in its Safe Practice 11 and the Society of Hospital Medicine $(9,10)$ have proposed discharge checklists that include:. reason for admission, key findings, laboratory tests, procedures and treatment, brief hospital course, reasons for medication change (s), discharge destination, discharge diagnosis, medications at discharge, follow-up appointments, proposed management plan, pending laboratory work, anticipated problems and suggested interventions and documentation of patients' education.

The relatively high omission rate of the "documentation of patient education" "pending laboratory work" "anticipated problems and suggested interventions" "medication change(s)" and "patient's discharge condition" we observed, could have important implications for future patients' care plans and health outcomes. Ideally, such information allows the OPD physicians to understand the patient's health and functional status at the time of hospital discharge, enabling them to better identify worrisome early changes in a vulnerable patient they, otherwise, do not know well. Such information is especially important because these patients are often unable to advocate for or provide medical information about themselves. They are an extremely medically complicated and vulnerable population, highly reliant upon the health care system to transmit information regarding their condition and care plan. Multiple experts, therefore, have recommended that detailed information concerning the patient's discharge condition be included in all hospital discharge summaries (11). Variability in discharge summaries and omission of important data occur not because physicians disagree on what needs inclusion but because they are busy and may not have time to adequately coordinate care with the primary care practice. Some studies $(12,13)$ have demonstrated a trend toward a decreased risk of readmission when the discharge summary arrives before the outpatient follow-up visit takes place. The study, by van-Walraven and colleagues, found a 0.74 relative risk of decreased rehospitalization for these patients, compared with when the summary did not arrive on time. Few medi- cal programs have policies to ensure speedy completion of discharge summaries and transmission to outpatient providers. The study (11) published in 2009 suggested several ways that physicians can ensure timely transmission of the discharge summary. These include automated red flags; for instance, a hospital can allow physicians to discharge a patient only when they enter the summary. Another solution to ensuring timely completion and delivery of discharge summaries is to deliver computer-generated discharge summaries by email, fax, post and patient hand delivery. According to a recent study that was published in 2010 by Chen and his colleagues (14), transmission of computergenerated discharge summaries by fax or email offers the most effective method of communicating with both patients and OPD physicians, as long as accurate contact information is available. Although fax is still the most preferred, email has many advantages that could potentially allow it to replace fax as a standard mode for delivery of discharge communication. These suggestions aimed at timely transfer of discharge summary, a goal which was not achieved in our study, since the availability of a finalized (typed and signed) discharge summary at the first post-discharge visit was very low (12.1\%) and remained poor at 4 weeks $(50.8 \%)$, affecting the quality of care in approximately $75 \%$ of follow-up visits and contributing to OPD- physician dissatisfaction. It seems that this defect is worldwide, as a review of the literature published in the year 2007 in the Journal of the American Medical Association (JAMA)(15) found that between $66 \%$ and $88 \%$ of discharge summaries were not sent to the outpatient provider in time for the follow-up visit, and for about $25 \%$ of patients, the outpatient physician did not receive the discharge summary at all.

Previous studies have examined primarily the presence or absence of key components of the discharge summaries $(15,16)$. In addition to the presence or absence of key items, our study also assessed, when present, the accuracy of these items compared to information contained in the hospital chart, giving a more complete assessment of the quality of the discharge summary. Most other studies have reported the results of questionnaires that asked physicians to draw on their recollection of recent experience for global feedback about what components of discharge summaries, in general, they find most important and most lacking (17-21). One study did elicit UK general practitioners' feedback about specific discharge summaries they received regarding their own patients discharged from hospital and found that $20 \%$ of respondents were dissatisfied with the content although the investigators did not quantify the nature of the deficiencies (22). Our study provides further empirical data at a patient-specific level during - real-life application about components of the discharge summary needing improvement. In addition, our study is novel because it highlights the deficiencies contained within discharge summaries specifically produced by junior residents, therefore identifying important priorities for a future educational intervention directed at junior learners. Finally, our study had the strength of assessments of the accuracy of dis- 
charge summaries by comparing it with the patient's own chart as standardized reference, and showed good interrater reliability. There are, however, some limitations. First, it is unclear whether these results are representative of other academic or community health care facilities in Saudi Arabia. Second, we assessed accuracy of the discharge summaries using the patient chart as the gold standard and it is possible that the medical record itself was inaccurate. A much more resource-intensive prospective study design would have been required to address this limitation and would not have been feasible for our project. Third, investigators performing the assessments of discharge summary completeness and accuracy were not blinded to the identity of the R1 residents who authored the summaries. Fourth, our sample was limited to internal medicine R-1 residents and thus the results are not necessarily generalizable to different resident levels or specialties. Additional research to examine the discharge summaries generated at other hospital departments is necessary to know whether the results presented here can be replicated.

\section{Conclusion and Recommendations}

Discharge summaries prepared by R1 physicians are grossly inadequate at documenting most of the essential domains described by the Joint Commission for Hospital Accreditation. Our findings will aid in the development of educational interventions for residents. The following may be recommended:

1. To hold didactic information sessions to all medical residents, outlining key components of a discharge summary.

2. Small group sessions involving review of desirable and undesirable discharge summaries are needed.

3. To focus on the importance of accuracy of the discharge summary, not just style,

4. To carry out periodic evaluation of discharge summaries by attending senior physicians.

5. To hold patients 'discharge until a discharge summary is completed.

6. To encourage electronic ways of delivering the discharge summaries to patients as well as OPD physicians.

\section{Acknowledgment}

The author thanks Professor A. Al-Quorain, Professor of Medicine and Gastroenterology for reviewing this manuscript and for his valuable advices. The author thanks Professor Fahd Al-Muhanna, Professor of Medicine and Nephrology for the great help he offered. The author also extends his appreciation to the Medical Record staff for their cooperation during the preparation of this study.

\section{Conflict of Interest}

The author declares that there is no conflict of interest concerning this work.

\section{References}

[1] Joint Commission on Accreditation of Healthcare Organization: Hospital national patient safety goals. 2010. www.jcrine.com/. Accessed August 19, 2012.

[2] Standard IM.6.10: Hospital Accreditation Standards. Oakbrook Terrace, Ill: Joint Commission on Accreditation of Healthcare Organizations; 2006:338-340.

[3] Joint Commission on Accreditation of Healthcare Organizations. Joint Commission national patient safety goals. http://www.jointcommission.org/PatientSafety/NationalPatie nt Safety Goals/. Accessed July 17, 2012.

[4] Rao P, Andrei A, Fried A, Gonzalez D, Shine D. Assessing quality and efficiency of discharge summaries. Am J Med Qual 2005; 20: 337-43.

[5] Coleman EA, Berenson RA. Lost in transition: challenges and opportunities for improving the quality of transitional care. Ann Intern Med. 2004; 141:533-536.

[6] van Walraven C, Mamdani M, Fang J, Austin P. Continuity of care and patient outcomes after hospital discharge. J Gen Intern Med. 2004;19:624-631.

[7] Landis JR, Koch GG. The measurement of observer agreement for categorical data. Biometrics 1977; 33: 159-74.

[8] Walraven C, Taljaard M, Bell CM, Etchells E, Stiell JG, Zarnke K, Foster AJ. A prospective cohort study found that provider and information continuity was low after patient discharge from hospital. J Clin Epidemiol 2010; 63: 10001010.

[9] National Quality Forum (NQF). Safe practices for better health care: a consensus report. Washington, DC: NQF, 2003.

[10] National Quality Forum (NQF). The National Quality Forum's consensus development process. Version 1. 7. Washington, DC: NQF, 2004.

[11] Kevin J, O'Leary M, Liebovitz DM, Feinglass J, Liss DT, Evans DB, Kulkarni N, Landler MP, Baker DW. Creating a better discharge summary: improvement in quality and timelines using an electronic discharge summary. Hosp Med 2009; 4: 219-25.

[12] van-Walraven C, Seth R, Austin PC, Laupacis A. Effect of discharge summary availability during post-discharge visits on hospital readmission. J Gen Intern Med. 2002;17:186-92.

[13] Li JY, Yong TY, Hakendorf P, Ben-Tovim D, Thompson CH. Timeliness in discharge summary dissemination is associated with patients' clinical outcomes. J Eval Clin Pract October, 2011; Published online by Blackwell Publishing Ltd. doi:10.111/j.1365-2753.2011.01772.x.

[14] Chen Y, Brennan N, Magrabi F. Is email an effective method for hospital discharge communication? A randomized controlled trial to examine delivery of computer-generated discharge summaries by email, fax, post and patient hand delivery. In J Med Inform 2010; 79: 167-72.

[15] Kripalani S, LeFevre F, Phillips CO, Williams MV, Bassaviah $\mathrm{P}$, Baker DW. Deficits in communication and information transfer between hospital-based and primary care phy- 
sicians: implications for patient safety and continuity of care JAMA 2007; 297: 831-41.

[16] Wilson S, Ruscoe W, Chapman M, Rhona-Miller RN. General practioners-hospital communications: a review of discharge summaries. J Qual Clin Pract 2001; 21: 104-08.

[17] Bado W, Williams CJ. Usefulness of letters from hospitals to general practitioners. BMJ 1984; 288: 1813-14.

[18] Munday A, Kelly B, Forrester J, Timoney A, McGovern E. Do general practitioners and community pharmacists want information on the reasons for drug therapy changes implemented by secondary care? Br J Gen Pract 1997; 47: 563-66.
[19] Newton J, Eccles M, Hutchinson A. Communication between general practioners and consultants: what should their letters contain? BMJ 1992; 304: 821-24.

[20] Pantilat SZ, Lindenauer PK, Katz PP, Watcher RM. Primary care physicians' attitudes regarding communication with hospitalists. Am J Med 2001; 111: 15S-20S.

[21] van Walraven C, Rokosh E. What is necessary for high quality discharge summaries? Am J Med Qual 1999; 14: 160-69.

[22] Harding J. Study of discharge communications from hospital doctors to an inner London general practice. J R Coll Gen Pract 1987; 37: 494-95. 